\title{
Albinism in childhood: a flash VEP and ERG study
}

\author{
Isabelle Russell-Eggitt, A Kriss, D S I Taylor
}

\begin{abstract}
Flash visual evoked potentials (F.VEPs) and electroretinograms (ERGs) were recorded in a total of 20 young children with albinism (age range 5 months to 11 years, mean 4 years). All recordings were made without sedation. There were 13 oculocutaneous cases (one with Hermansky-Pudlak syndrome) and seven ocular albinos. Monocular flash stimulation commonly elicited an asymmetrical occipital VEP distribution with a well lateralised component at around $80 \mathrm{~ms}$ which was of opposite polarity in a comparison of VEPs from each eye. None of the normally pigmented matched controls or obligate female carriers showed this anomalous distribution. The albino electroretinogram, compared with controls, recorded under fully darkened conditions had a significantly larger a wave and significantly shorter latencies for both $a$ and $b$ waves. The accentuated ERG and asymmetrical VEP recorded in infants and young children with albinism permits distinction of these patients from those with congenital cone dysfunction and idiopathic nystagmus, with whom they may be confused by a clinical examination only.
\end{abstract}

Albinism is a genetically determined heterogeneous group of disorders involving deficiency of the enzyme tyrosinase, which mediates conversion of tyrosine to the pigment melanin. ${ }^{12}$ At least 10 forms of albinism have been described. ${ }^{3-5}$ The commonest are autosomal recessive oculocutaneous albinism, in which skin, hair, and eyes are conspicuously involved, and $\mathrm{X}$-linked ocular albinism, in which the hypopigmentation predominantly involves the eye. ${ }^{6}$ Various non-allellic forms of oculocutaneous albinism occur. The children of two parents with different forms of albinism are likely to be normally pigmented. ' 'Ocular' albinism does not solely affect the eyes; there is also less evident pigment dilution of skin and hair. If parents have dark brown hair with olive skin, the ocular albino child may have light brown hair that darkens slightly with age and fair skin that tans. The skin in ocular albinism and also in heterozygotes contains abnormal giant melanosomes, ${ }^{8-10}$ but this feature is not unique to albinism. " 12

The degree of ocular hypopigmentation in albinism varies. ${ }^{3}$ The irides are usually translucent ${ }^{+}$; this condition may be gross, especially in oculocutaneous albinism, when the lack of uveal pigment gives a 'pink eyed' appearance. In ocular albinism the irides may be brown, though usually the mid stroma transilluminates. Patients may be photophobic, but this is not a constant feature. The fundus is hypopigmented, with conspicuous large choroidal vessels. There may be a marked reduction of vessels forming the perimacular arcades. ${ }^{13}$ The foveal region is not formed ${ }^{14}$ and the optic disc may be hypoplastic. ${ }^{13}$

Female heterozygotes display a mosaic fundal appearance with small patches of hypopigmentation intermixed with pigmented areas. ${ }^{15}$ However, the fundal picture varies, and both obligate heterozygotes without fundus changes ${ }^{916}$ and female heterozygotes who are as severely affected as male offspring ${ }^{17}$ have been reported. This variation in expression can be explained by the Lyonisation effect. ${ }^{18}$

Visual acuity and contrast sensitivity are usually reduced in all forms of albinism. ${ }^{19}{ }^{20}$ Both myopic and hypermetropic refractive errors are common. ${ }^{21}$ Furthermore, there is a high incidence of squint and nystagmus. ${ }^{2122}$ The nystagmus is usually pendular and horizontal, but there may be a rotary component, and it may become jerky on lateral gaze. ${ }^{23}$ The nystagmus often dampens when close vision is being used and, conversely, becomes more marked in bright illumination, with resultant reduction in vision. ${ }^{23}$ The intensity of the nystagmus often lessens with age, and this may be associated with improvement in visual performance. $^{23}$

All albino mammals appear to have anomalous projection of fibres in both the visual ${ }^{2024-34}$ and auditory modalities ${ }^{35}{ }^{36}$ (Fig 1). In the normally pigmented person fibres derived from the nasal half of the retina of each eye decussate at the chiasm, while temporal retinal fibres are uncrossed and project to the ipsilateral hemispere. In albinos the majority of temporal retina fibres subserving the nasal field (from fixation to
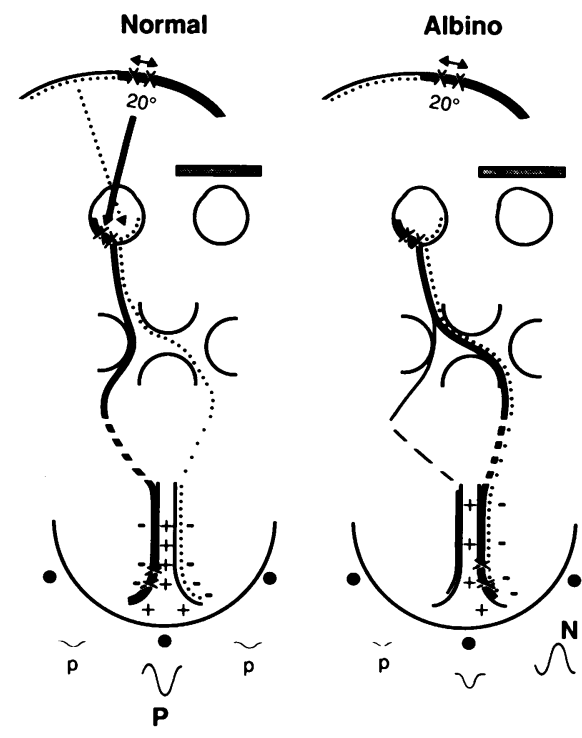

Figure 1: Diagram of visual pathway from one eye in a normal control and an albino. In the albino, temporal retinal fibres subserving the nasal field from the fixation point to an eccentricity of $20^{\circ}$ project anomalously to the contralateral hemisphere. 
TABLE I Hair colour may indicate tyrosinse activity in the oculocutaneous albinos $(0-c)$. An improvement in visual behaviour, 'delayed visual maturation' (DVM), was noted in eight cases (asterisks). The most recent visual acuity is recorded in Snellen or in cycles/degree for the acuity card procedure. Central figures are for binocular acuities. $H-P$ is the Hermansky-Pudlak case

\begin{tabular}{|c|c|c|c|c|c|c|}
\hline \multirow[b]{2}{*}{ Patient } & \multirow{2}{*}{$\begin{array}{l}\text { Age at } \\
\text { electrodiagnosis }\end{array}$} & \multirow[b]{2}{*}{ Diagnosis } & \multirow[b]{2}{*}{ Hair colour } & \multirow[b]{2}{*}{$D V M$} & \multicolumn{2}{|l|}{ Acuity } \\
\hline & & & & & Right & Left \\
\hline 1 & $9 \mathrm{mo}$ & $0-c$ & Golden & * & & \\
\hline 2 & $10 \mathrm{mo}$ & $0-c$ & White & & & \\
\hline 3 & $5 \mathrm{yr}$ & $0-c$ & White & * & $4 / 60$ & $4 / 36$ \\
\hline 4 & $9 \mathrm{yr}$ & $0-c$ & White & & $6 / 60$ & $6 / 60$ \\
\hline 5 & $7 \mathrm{yr}$ & $0-c$ & White & & $6 / 18$ & $6 / 60$ \\
\hline 6 & $18 \mathrm{mo}$ & $0-c$ & White & $\star$ & \multirow{2}{*}{\multicolumn{2}{|c|}{$\begin{array}{c}3 \mathrm{cy} / \mathrm{d} \\
4 / 24\end{array}$}} \\
\hline 7 & $2 \mathrm{yr}$ & $0-c$ & White & $\star$ & & \\
\hline 8 & $7 \mathrm{mo}$ & $0-c$ & White & $\star$ & & \\
\hline 9 & $5 \mathrm{mo}$ & $0-c$ & Golden & $\star$ & & \\
\hline 10 & $5 \mathrm{yr}$ & $0-c$ & Golden & & $6 / 60$ & $5 / 60$ \\
\hline 11 & $8 \mathrm{yr}$ & $0-c$ & Golden & & $6 / 36$ & $6 / 18$ \\
\hline 12 & $7 \mathrm{mo}$ & $0-c$ & White & & & \\
\hline 13 & $4 \mathrm{yr}$ & H-P & Golden brown & & $6 / 24$ & $6 / 24$ \\
\hline 14 & $7 \mathrm{mo}$ & Ocular & Golden & $\star$ & $4 \mathrm{c}$ & $15 / 12)$ \\
\hline 15 & $7 \mathrm{yr}$ & Ocular & Brown & & $6 / 60$ & $6 / 24$ \\
\hline 16 & $9 \mathrm{yr}$ & Ocular & Light brown & & $5 / 60$ & $5 / 60$ \\
\hline 17 & $6 \mathrm{yr}$ & Ocular & Light brown & & $6 / 60$ & $6 / 60$ \\
\hline 18 & $9 \mathrm{yr}$ & Ocular & Brown & & $6 / 24$ & $6 / 24$ \\
\hline 19 & $11 \mathrm{yr}$ & Ocular & Brown & & $6 / 36$ & $6 / 60$ \\
\hline 20 & $8 \mathrm{mo}$ & Ocular & Golden & $\star$ & $6 / 18$ & \\
\hline
\end{tabular}

an eccentricity of about $20^{\circ}$ ), anomalously cross with the nasal retinal fibres (Fig 1). Monocular visual evoked potentials (VEPs) to flash are reported to have a contralateral emphasis in $70 \%$ of adult albinos, ${ }^{25}$ though no detailed specification of components was made. This VEP effect most probably reflects the abnormal fibre projection pattern in albinism.

All adult albinos are reported to have an abnormal contralateral emphasis for pattern onset reponses, ${ }^{30}$ but the same group of workers found only $33 \%$ of albino children appear to have similar abnormalities. ${ }^{33}$

Boylan $^{32}$ recorded flash VEPs in three young infants (aged 1, 4.5, and 7 months) and reported a predominant late positivity $(150-316 \mathrm{~ms})$ on the side of scalp contralateral to the eye stimulated. ${ }^{32}$ Recently Guo et $a l^{37}$ recorded from 19 albino patients aged between 1.5 and 20 years and found that in $88 \%$ of patients the flash VEP main positivity on the ipsilateral side of the scalp was significantly delayed and in $59 \%$ of patients this component was attenuated.

This paper describes consistent ERG differences in young albino children compared with controls, and specific flash VEP changes at a latency of about $80 \mathrm{~ms}$, not reported before. Our technique demonstrates a very high detection rate and is relatively easy to perform in infants. This specific pattern of abnormality found in albinism allows ready distinction from other conditions, such as cone dysfunction and idiopathic nystagmus, with which it may easily be confused on purely clinical grounds.

\section{Patients and methods}

A series of 20 albino patients -13 oculocutaneous (one Hermansky-Pudlak) and seven ocular albinos - were clinically examined. Visual acuity testing (with the acuity card procedure in the preverbal), slit-lamp examination of iris translucency, cycloplegic retinoscopy, and fundus examination (where possible including photography) were all carried out. Immediate relatives were also examined when they were available. A full history was taken, with special emphasis on ocular details.
Electrophysiological recordings were obtained without pupil dilatation, and none of the patients was sedated. Recordings were also made on three carrier mothers; two of them were recorded with undilated pupils. In one carrier only one of the pupils was dilated (Fig 2).

The age range of the albino patients was 5 months to 11 years; the group mean was 4.3 years (SD 3.5). Recordings from the patients were compared with those of normally pigmented matched controls of similar age (mean age 5 years, SD 3.14).

Silver/silver chloride EEG electrodes were attached to the lower eyelid, within $1 \mathrm{~cm}$ of the eyelid margin, and across the posterior scalp. Occipital electrodes were placed at $\mathrm{O}_{z}[(10-20$ system), approximately $3 \mathrm{~cm}$ above the inion] and at approximately $4 \mathrm{~cm}$ either side of $\mathrm{O}_{z}(20 \%$ of the ear to ear distance through $\mathrm{O}_{\mathrm{z}}$ ). The eye and occipital electrodes were all referred to a common mid-frontal reference $\left(F_{z} ; 10-20\right.$ system). The clinical neurophysiology convention of 'negative upwards' was used to display the VEP. For consistency, ERG traces were displayed by this convention also.

A Grass photic stimulator (Model PS22, intensity setting $4,4 \cdot 75 \times 10^{6}$ lumens) was used to present flash stimuli at $3 / \mathrm{s}$ under fully darkened conditions. The recording amplifier bandpass was $3-125 \mathrm{~Hz}$, and 128 responses were averaged for each run. The sweep duration was $300 \mathrm{~ms}$, which included a $15 \mathrm{~ms}$ prestimulus interval.

Flash VEPs were recorded in all 20 patients. ERG recordings were obtained in 16 patients. Four of the younger patients would not accept electrodes under their eyes.

\section{Results}

The ocular findings and general pigmentation of subjects are summarised in Table I. The mothers and other immediate female relatives of three male cases with ocular albinism did not show a mosaic fundus pattern. In these cases, therefore, it was not possible to distinguish between an autosomal recessive and an X-linked inheritance pattern. One patient was atypical in that he also had bilateral partial iris colobomata inferiorly and had developed posterior subcapsular cataracts requiring lensectomy at age 6 years.

Less than half of the patients with oculocutaneous and ocular albinism $(8 / 20)$ had very poor purposive visual behaviour for the first 2-3 months after birth. Vision then gradually improved, though eventual acuity levels never approached normal levels.

Figure 2 shows the flash ERG and VEP traces of two patients with oculocutaneous albinism (left side), and those of a patient with X-linked ocular albinism and his mother's (obligate carrier) (right side). All three albino patients had a conspicuous VEP asymmetry. On each side of the midline (arrowed) there were components of opposite polarity which showed an apparent polarity inversion when responses were compared from each eye (crossed asymmetry). In contrast, VEPs from the carrier (lower right traces) had normal features. They were symmet- 
Figure 2: Retinal and occipital responses in cases with albinism

(oculocutaneous - upper left, ocular-upper right,

Hermansky-Pudlak - lower left) and in a female carrier (mother of the albino case lower right). Note the accentuated a wave in $E R G$ and marked VEP

asymmetry in all albino cases, but not in the female carrier.

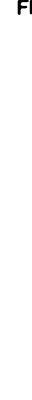

lash

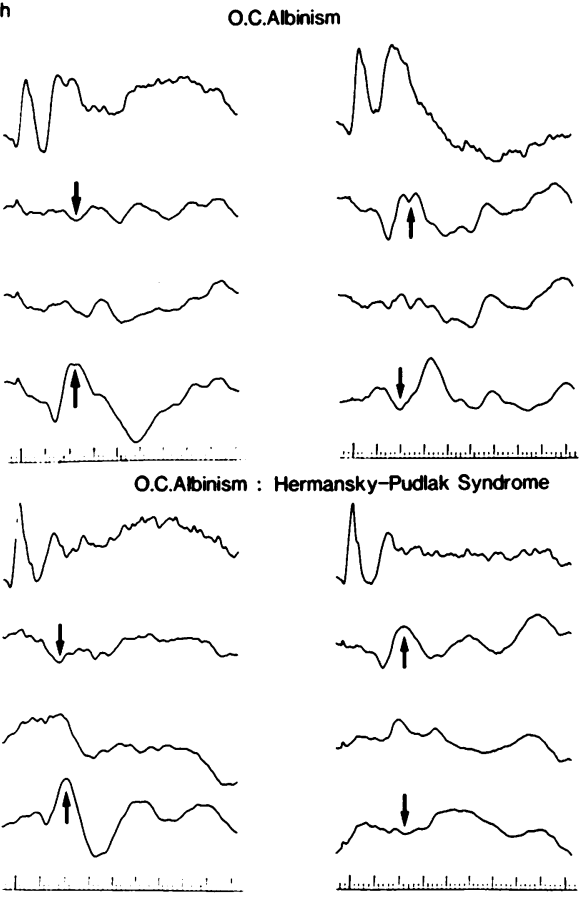

Flash

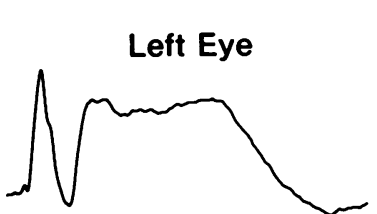

Albinos
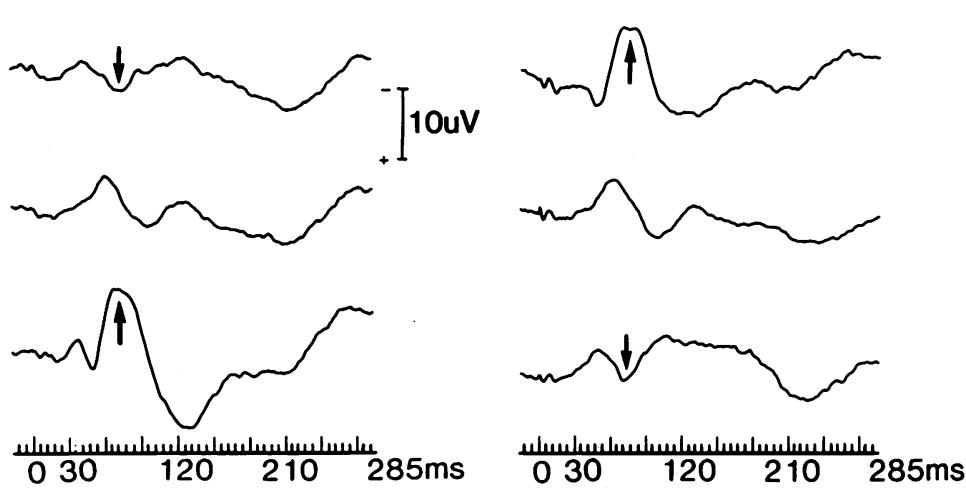

Matched Controls
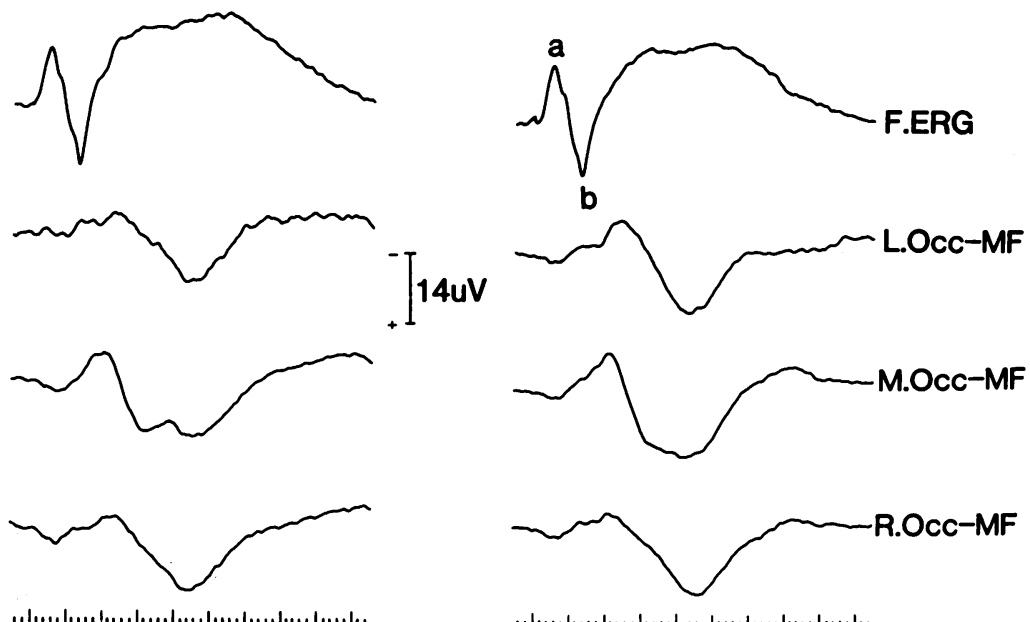

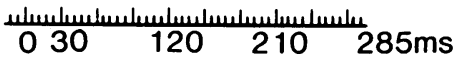

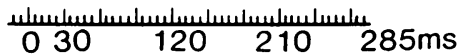

Figure 3: Group average ERGs and VEPs for albino patients (upper traces), and matched controls (lower traces). Note accentuated ERG a wave and VEP crossed asymmetry in albino recordings.
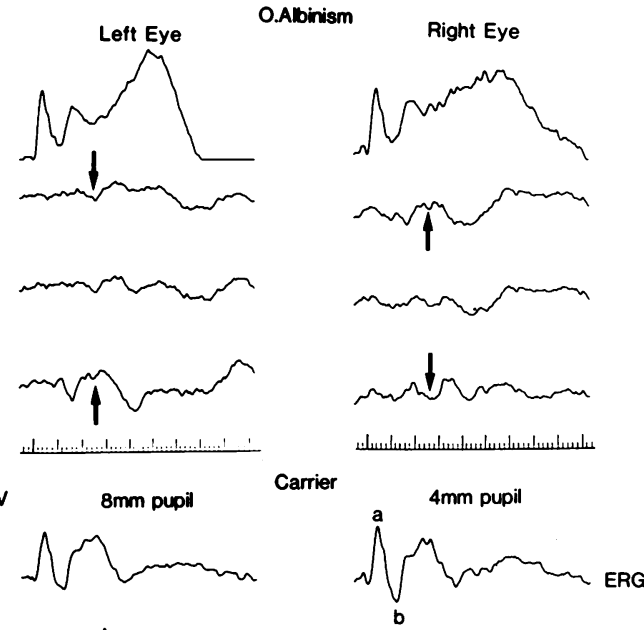

anding prownen
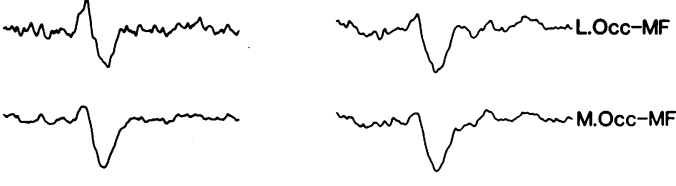

רon

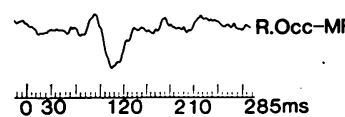

rical about the midline and were similar for the two eyes.

All 20 albino patients showed similar crossed asymmetry features, which were most conspicuous and consistent at a latency around $80 \mathrm{~ms}$.

Figure 3 shows the group average ERGs and VEPs for the albino patients (upper traces) and for matched controls (lower traces). Note the marked VEP asymmetry in the albino group, which is best seen on each side of the midline at around $80 \mathrm{~ms}$. For left eye stimulation a prominent negativity is recorded over the right occipital scalp (contralateral N80-C.N80), and a smaller component at the same latency is present at the left occipital electrode (ipsilateral P80-I.P80). For right eye stimulation the distribution is reversed, with a negativity over the left occipital area (C.N80) and a positivity over the right (I.P80). The contralateral N80 is followed by a larger positivity of more variable form and latency (range 96-178 ms, mean $129.3 \mathrm{~ms}$, SD $19 \cdot 3$, amplitude $16 \cdot 0 \mu \mathrm{V}$, SD $5 \cdot 5$; C.P130).

Tables II and III summarise the amplitude and latency data for all albino patients. The mean and standard deviations of C.N80 and I.P80 for

TABLE II Albino flash VEP. Mean latency (ms) and standard deviation for ipsilateral and contralateral component at $80 \mathrm{~ms}$

\begin{tabular}{llcc}
\hline & & I.P80 & $C . N 80$ \\
\hline Left eye: & Mean & $79 \cdot 05$ & 76.53 \\
Right eye: & SD & $12 \cdot 33$ & $8 \cdot 57$ \\
& Mean & $87 \cdot 28$ & $75 \cdot 85$ \\
& SD & 10.85 & $7 \cdot 71$ \\
\hline
\end{tabular}

TABLE III Albino flash VEP. Mean amplitude $(\mu V)$ ipsilateral and contralateral components at $80 \mathrm{~ms}$

\begin{tabular}{llll}
\hline & & $I . P 80$ & $C . N 80$ \\
\hline Left eye: & Mean & $7 \cdot 82$ & $10 \cdot 13$ \\
& SD & 3.81 & 4.48 \\
Right eye: & Mean & 5.49 & $8 \cdot 89$ \\
& SD & 3.34 & 4.42
\end{tabular}


TABLE IV Flash ERG latency (ms)

\begin{tabular}{llrrrrr}
\hline & & \multicolumn{3}{c}{ Left eye } & & \multicolumn{2}{c}{ Right eye } \\
\cline { 3 - 4 } \cline { 5 - 6 } & & $a$ & $b$ & & \multicolumn{1}{c}{$b$} \\
\hline Albino patients & Mean & 14.55 & 36.08 & & 14.58 & 35.63 \\
$n=16$ & SD & 0.86 & 3.14 & 0.6 & 3.53 \\
Controls & Mean & 15.65 & 39.15 & 16.13 & 39.53 \\
$n=16$ & SD & 1.61 & 1.06 & 1.81 & 1.48 \\
Significance & $\mathrm{p}$ & $<0.02$ & $<0.01$ & $<0.01$ & $<0.01$ \\
\hline
\end{tabular}

TABLE V Flash ERG amplitude $(\mu V)$

\begin{tabular}{|c|c|c|c|c|c|}
\hline & \multicolumn{2}{|c|}{ Left eye } & \multicolumn{2}{|c|}{ Right eye } \\
\hline & & $a$ & $b$ & $a$ & $b$ \\
\hline $\begin{array}{l}\text { Albino patients } \\
n=16 \\
\text { Controls } \\
n=16 \\
\text { Significance }\end{array}$ & $\begin{array}{l}\text { Mean } \\
\text { SD } \\
\text { Mean } \\
\text { SD } \\
\mathrm{p}\end{array}$ & $\begin{array}{r}16.97 \\
6.45 \\
11.62 \\
4.63 \\
<0.01\end{array}$ & $\begin{array}{l}21 \cdot 6 \\
11 \cdot 91 \\
28 \cdot 12 \\
8 \cdot 03 \\
\mathrm{NS}\end{array}$ & $\begin{array}{r}17 \cdot 94 \\
7 \cdot 45 \\
12 \cdot 29 \\
4 \cdot 04 \\
<0 \cdot 01\end{array}$ & $\begin{array}{c}21 \cdot 91 \\
13 \cdot 47 \\
28 \cdot 35 \\
7 \cdot 77 \\
\text { NS }\end{array}$ \\
\hline
\end{tabular}

the left and right eye stimulation are given. In general, the C.N80 component was the larger, more conspicuous component (mean amplitude $9.4 \mu \mathrm{V}$ ) and was detectable in 37 of 40 monocular records (93\%). The ipsilateral component (I.P80) on average measured $6.6 \mu \mathrm{V}$ and was present in 32 of the 40 monocular records (80\%). Both C.N80 and I.P80 were together present in 30 of the 40 monocular records $(75 \%)$.

There were no significant latency or amplitude differences when the same component was compared in the response from each eye. Both oculocutaneous and ocular albinos showed the crossed asymmetry features with equal clarity.

The flash VEP of controls had a different emphasis. The C.N80 and I.P80 components were not apparent in control recordings. Instead control subjects had a virtually symmetrical VEP distribution with a midline negativity, with a mean latency of $63 \mathrm{~ms}$ (SD 6.7) and amplitude of 8.7 $\mu \mathrm{V}$ (SD 5.6). This was followed by a conspicuous positivity peaking, on average, at 95 ms (SD 8.9) with an amplitude of $23.7 \mu \mathrm{V}$ (SD 7.9).

The averaged flash ERGs of albinos showed statistically significant differences from those of normally pigmented controls of the same age (Tables IV and V). On average, the a wave was $40-50 \%$ larger in albinos $(\mathrm{p}<0.01)$. The mean b/a amplitude ratio for the albino ERGs was $1 \cdot 26$ (SD 0.39), and this was significantly different $(p<0.01)$ from the ratio of $2.51($ SD 1.1) for the age matched control group. The $a$ and $b$ wave latencies were earlier in albinos than in controls by 1 and 3 ms respectively $(\mathrm{p}<0.02)$.

\section{Discussion}

Our results agree with those of other studies showing that albinos have monocular flash VEPs which are prominent on the side of the scalp contralateral to the stimulated eye. ${ }^{2527303137}$ However, unlike those previous studies we report a consistent negative component at around $80 \mathrm{~ms}(\mathrm{C} . \mathrm{N} 80)$ which is prominent on the side of the scalp contralateral to the stimulated eye and is usually, though not always, accompanied by a concurrent ipsilateral positivity (I.P80). Following the contralateral negativity (C.N80) there is a positivity of more variable latency and amplitude (C.P130).
This specific occipital asymmetry at around 80 ms was not observed in normally pigmented controls. The highly consistent latency relationship between I.P80 and C.N80 components strongly suggests a common generator with a dipole property. This explanation would be analogous to that used to account for the distribution of the somewhat later P100 component of the pattern reversal response to half field stimulation in normally pigmented control subjects. ${ }^{38}$ However, the possibility of independent generators for C.N80 and I.P80 cannot be completely excluded, as occasionally only one of these lateralised components was recordable.

If the dipole hypothesis is invoked, then the waveform recorded in the midline is likely to represent a transitional waveform similar to that observed following half field pattern reversal stimulation in controls. ${ }^{39}$ Thus, it is suggested that in the albino most fibres representing central areas of the visual field from one eye project to medial aspects of the contralateral occipital hemisphere. In the albino infant and young child, at least, activation of this area produces an early positivity at the cortical surface which is picked up by the ipsilateral electrode (I.P80). A coincident negativity is present at the deeper cortical layers, and this is best picked up by the contralateral electrode (C.N80). Presumably the C.N80 component tends to be larger than I.P80, as the contralateral scale electrodes are closer to the generator area than are ipsilateral scalp electrodes.

It is not clear at present why this activity at 80 $\mathrm{ms}$ is not apparent in the records of normal controls. One possibility is that in controls it is present but masked by activity arising from the cortical foveal representation, not present in albinos.

We recorded flash VEPs using a monopolar derivation widely spaced occipital electrodes, 4-5 cm from the midline, referred to a distant midfrontal electrode. Others have used a bipolar montage with occipital electrodes nearer to the midline (approximately $3 \mathrm{~cm}$, at $\mathrm{O}_{1}$ and $\mathrm{O}_{2}$, of the $10-20$ system) and used nearby ipsilateral references either at the ear ${ }^{37}$ or at central scalp locations. ${ }^{32}$ Such derivations are suboptimal, as they span the occipital areas over which VEP activity is prominent (see Kriss ${ }^{40}$ for fuller discussion). The $80 \mathrm{~ms}$ component was of consistent latency when comparing individuals, and there was no evidence of ipsilateral or contralateral 'delays' reported by others. ${ }^{32}{ }^{37}$ We found that the C.N80 component was often followed by a somewhat variable positive component at $\mathbf{1 3 0}$ ms (C.P130). It is probably this contralateral component that some previous studies have reported on. ${ }^{32}$

Our ERG findings broadly agree with those of Krill and Lee, ${ }^{41}$ who found, using the conventional corneal ERG, single flash technique, elicited under dark adapted conditions, that both oculocutaneous (five cases) and ocular albinos (three cases) had significantly larger $a$ and $b$ waves, and shorter latencies for these components compared with normally pigmented controls. Six carriers of the X-linked condition showed no difference compared with controls.

The ERG differences can most probably be 
ascribed to the stronger effects of the flash stimulus on the albino eye, owing to more light entering through the translucent iris, as well as greater fundal reflectance and light scatter because of lack of retinal pigment absorption. Similar $a$ and $b$ wave changes are recorded from the normally pigmented eye with very bright flashes. With increasing flash intensity the a wave progressively enlarges, but the $b$ wave saturates and at very high intensities attenuates to a small extent. ${ }^{+2}$ The discrepancy between our study and that of Krill and Lee ${ }^{+1}$ for the b amplitude is most probably due to differences in the intensity of the flash stimulus (not specified by Krill and Lee).

It can sometimes be difficult, when relying soley on a clinical examination to be certain whether an infant with nystagmus has congenital cone dysfunction or ocular albinism. In both conditions photophobia may be prominent. In our experience the ERG and VEP findings in albinism are specific and are thus very useful in helping to make a differential diagnosis between these two conditions. Furthermore we find that the crossed asymmetry VEP pattern is not found in other conditions in which nystagmus is conspicuous, such as congenital motor nystagmus or latent nystagmus associated with dissociated vertical deviation. ${ }^{+3}$

We thank the Iris Fund for its generous support.

1 Garrod AE. Inborn errors of metabolism. Croonian lectures, lecture 1. Lancet 1908; ii: 1-7.

2 Durham FH. On the presence of tyrosinase in the skin of some pigment vertebrates. Proc $R$ Soc Lond 1904; 74: 310-3.

3 Kinnear PE, Jay B, Witkop CJ. Albinism. Surv Ophthalmol 1985; 30: 75-101

4 Jay B, Caruthers J, Treplin MCW, Winder AF. Human albinism. Birth Defects 1976; 12: 415-26.

5 Witkop CJ, Hill CW, Desnik S, et al. Ophthalmologic, biochemical, platelet, and ultrastructural defects in th various types of oculocutaneous albinism. F Invest Dermatol 1973; 60: 443-56.

6 Nettleship E. The Bowman lecture. On hereditary diseases of the eye. Trans Ophthalmol Soc UK 1909; 29: 57-198.

7 Trevor-Roper PD. Marriage of two complete albinos with normally pigmented offspring. Br 7 Ophthalmol 1952; 36: $107-8$.

8 Cortin P, Tremblay M, Lemagne JM. X-linked ocula albinism: relative value of skin biopsy, iris transillumination and funduscopy in identifying affected males and carriers. Can f Ophthalmol 1981;16: 121-3.

9 Garner A, Jay BS. Macromelanosomes in X-linked ocular lbinism. Histopathology $1980 ; 4: 243-54$

10 O'Donnell FE Jr, Hambrick GW Jr, Green WR, et al. $\mathrm{X}$-linked ocular albinism, an oculocutaneous macromelanosomal disorder. Arch Ophthalmol 1976; 94: 1883-92.

11 Guerrier CJ, Lutzner MA, Devico V, Prunieras M. An electron microscopical study of the skin in 18 cases of xeroderma pigmentosum. Dermatologica 1973; 146: 211-21.

12 Benedict PH, Szabo G, Fitzpatrick TB, Sinesi SJ. Melanotic macules in Albright's syndrome and in neurofibromatosis. IAMA 1968;205:618-26.

13 Spedick MJ, Beauchamp GR. Retinal vascular and optic nerve abnormalities in albinism. I Pediatr Ophthalmol Strabismus 1986; 23: 58-63.

14 Usher $\mathrm{CH}$. Histological examination of a human albino's eyeball. Biometrika 1920; 13: 46-56.
15 Falls HF. Sex-linked ocular albinism displaying typical fundus changes in the female heterozygote. Am $\mathcal{F}$ Ophthalmol 1951; 31 (suppl): 41-50

16 Gillespie FD, Covelli B. Carriers of ocular albinism with and without ocular changes. Arch Ophthalmol 1963; 70: 209-13.

17 Jaeger C, Jay B. X-linked ocular albinism. A family containing manifesting heterozygote, and an affected male married to a female with autosomal recessive ocular albinism. Hum Genet 1981; 56: 299-304.

18 Lyon MF. Sex chromatin and gene action in the mammalian $\mathrm{X}$ chromosome. Am F Hum Genet 1962; 14: 135-48.

19 Wilson HR, Mets MB, Nagy SE, Kressel AB. Albino spatial vision as an instance of arrested visual development. Vision Res 1988; 28: 979-90.

20 St John R, Timney B. Sensitivity deficits consistent with aberant crossed visual pathways in human albinos. Invest Ophthalmol Vis Sci 1981; 21: 873-7.

21 Fonda G, Thomas H, Gore GV. Educational and vocational placement and low contrast corrections in albinism. Sight Sav Rev 1971; 41: 29-35.

22 Falls HF. Albinism. Ophthalmology 1953; 57: 324

23 Krill AE. Clinical characteristics. In: Krill's Hereditary retinal and choroidal diseases. Hagerstown: Harper and Row, 1977; 2: 645-63.

24 Lund RD. Uncrossed visual pathways of hooded and albino rats. Science 1965; 149: 1506

25 Creel D, Witkop CJ, King RA. Asymmetric visually evoked potentials in human albinos: Evidence for visual system anomalies. Invest Ophthalmol Vis Sci 1974; 13: 430-40.

26 Creel D, O'Donnell FE, Witkop CJ. Visual system anomalies in human ocular albinos. Science 1978; 201: 931-3.

27 Coleman J, Syndor CF, Wolbarsht ML, Bessler M. Abnorma visual pathways in human albinos studied with visually evoked potentials. Exp Neurol 1979; 65: 667-79.

28 Carroll WM, Jay BS, McDonald WI, Halliday AM. Pattern evoked potentials in human albinism. Evidence of two evoked potentials in human albinism. Evidence of two different topographical asymmetries reflecting abnorm
retino-cortical projections. $\mathcal{F}$ Neurol Sci $1980 ; 48: 265-87$.

29 Creel D, Spekreijse H, Reits D. Evoked potentials in albinos: efficacy of pattern stimuli in detecting misrouted optic fibres. Electroencephalogr Clin Neurophysiol 1981; 52: 595 603

30 Apkarian P, Reits D, Spekreijse H, Van Dorp D. A decisive electrophysiological test for human albinism. Electroencephalogr Clin Neurophysiol 1983; 55: 513-31.

31 Boylan C, Clement RA, Harding GFA. Lateralisation of the flash visually-evoked cortical potential in human albinos. Invest Ophthalmol Vis $S$ ci 1984; 25: 1448-50.

32 Boylan C, Clement RA, Harding GFA. Lateralisation of the flash visually evoked cortical potential in albino babies. Electroencephalogr Clin Neurophysiol 1985; 60:500-3.

33 Apkarian P, Spekreijse H. The VEP and misrouted pathways in human albinism. In: Cracco RA, Bidis-Wollner I, eds. in human albinism. In: Cracco RA, Bidis-Woll

34 Lund RD. Pigment and visual projections. Nature 1986; 321 203-4.

35 Creel D, Garber SG, King RA, Witkop CJ. Auditory brain stem anomalies in human albinos. Science 1980; 209 1253-5.

36 Fisch L. Deafness as part of an hereditary syndrome. 7 Laryngol Otol 1959; 73: 355-82.

37 Guo S, Reinecke RD, Fendick M, Calhoun JH. Visual pathway abnormalities in albinism and infantile nystagmus, VECPs and stereoacuity measurements. $f$ Pediatr Ophthalmol Strabismus 1989; 26: 97-104.

38 Barrett G, Blumhardt L, Halliday AM, Halliday E, Kriss A A paradox in the lateralization of the visual evoked response. A paradox in the lateraliz

39 Blumhardt LD, Barrett G, Halliday AM, Kriss A. The effect of experimental 'scotomata' on the ipsilateral and contralateral responses to pattern reversal in one half field. Electroencephalogr Clin Neurophysiol 1978; 45: 376-92.

$40 \mathrm{Kriss}$ A. Setting up an evoked potential (EP). In: Halliday $\mathrm{AM}$, ed. Evoked potentials in clinical testing. Edinburgh: Churchill Livingstone, 1982: 23-8.

41 Krill AE, Lee GB. The electroretinogram in albinos and carriers of ocular albino trait. Arch Ophthalmol 1963; 69: 32-8.

42 Galloway NR. Ophthalmic electrodiagnosis. London: Lloyd Luke, 1981: 72-9.

43 Kriss A, Timms C, Elston J, Taylor D, Gresty M. Visual evoked potentials in dissociated vertical deviation: reappraisal. BrF Ophthalmol 1989; 73: 265-70. 